\title{
Effectiveness of Bumetanide Infusion in Treatment of Generalized Edema and Congestive Heart Failure
}

\author{
Anil K. Mandal1,2,3 \\ ${ }^{1}$ Putnam Community Medical Center, Palatka, Florida, USA \\ ${ }^{2}$ Flagler Hospital, St. Augustine, Florida, USA \\ ${ }^{3}$ University of Florida, Gainesville, Florida, USA \\ Email: amandal@med-spec.com
}

Received 17 July 2014; revised 9 August 2014; accepted 1 September 2014

Copyright (C) 2014 by author and Scientific Research Publishing Inc.

This work is licensed under the Creative Commons Attribution International License (CC BY). http://creativecommons.org/licenses/by/4.0/

(c) (i) Open Access

\begin{abstract}
Generalized edema (anasarca) is common in nephrotic syndrome which rarely produces shortness of breath. Increased shortness of breath associated with rapid weight gain and generalized edema signify congestive heart failure (CHF). Loop diuretics consisting of furosemide (Lasix ${ }^{\circledR}$ ), bumetanide (Bumex ${ }^{\circledR}$ ), torsemide (Demadex ${ }^{\circledR}$ ) or ethacrynic acid (Edecrin) are effective diuretics to treat anasarca. However, efficacy varies depending on the renal function. Loop diuretic given orally or by intravenous boluses produce good urine output but overall response in reducing edema or shortness of breath as in CHF is less than optimum. Although literature information is very limited, continuous bumetanide infusion for 72 to 96 hours is found to be very effective in producing subjective relief of shortness of breath as well as objective improvement such as reduction in brain natriuretic peptide in CHF and improved kidney function, so that diuresis is sustained even after discontinuation of the infusion. Decrease in kidney function and electrolytes and acid-base imbalance are common but they are reversible with prompt replacement therapy. They pose no threat to life.
\end{abstract}

\section{Keywords}

Bumetanide Infusion, Generalized Edema, Congestive Heart Failure

\section{Anatomy and Pathophysiology of Edema}

Edema is defined as the presence of excessive amount of fluid in the tissue of the body. Fluid accumulates 
mainly in the extracellular fluid compartment (ECFC), but it can also accumulate in the intracellular fluid compartment (ICFC).

ECFC consists of

\section{1) Intravascular fluid space}

2) Interstitial fluid space

Fluid is filtered from the intravascular fluid space into the interstitial fluid space at the arteriolar end of the capillary and then returns into the intravascular fluid space at the venous end of the capillary. This is a continuous process and effected mainly by the difference in the gradient between the hydrostatic pressure at the venous end of the capillary and the oncotic pressure exerted by intravascular (plasma) albumin concentration. Thus pathologically, if the venous pressure is very high as in congestive heart failure (CHF), large amount of fluid will be filtered in the interstitial fluid space. Similarly, if plasma oncotic pressure is low due to low albumin concentration as in nephrotic syndrome or cirrhosis of liver, fluid will stagnate in the interstitial fluid space.

Under normal conditions, fluid does not accumulate in the interstitial fluid space as fluid pressure remains negative, hence no edema is detected.

Total edema safety factor against edema formation is $17 \mathrm{mmHg}$ negative pressure and includes:

Interstitial fluid pressure $-7 \mathrm{mmHg}$

Lymphatic flow $-6 \mathrm{mmHg}$

Lymphatic washout of protein $-4 \mathrm{mmHg}$

Total $-17 \mathrm{mmHg}$

When fluid continues to accumulate in the interstitial fluid space as by increased venous pressure or reduced plasma albumin concentration, interstitial fluid pressure increases in parallel with fluid volume. Thereby, negative interstitial fluid pressure is dissipated, and interstitial fluid pressure rises to the positive range giving rise to detectable edema. Therefore, excessive fluid accumulation in the interstitial fluid space initially may occur in one of the following two ways.

a) Abnormal leakage of fluid from the blood capillaries.

b) Reduced plasma oncotic pressure due to low plasma albumin concentration.

a) Abnormal leakage of fluid from the capillaries may occur in CHF, acute glomerulonephritis, angioedema, venous obstructions such as inferior vena cava thrombosis or subclavian vein thrombosis caused by a catheter placement for temporary or long term hemodialysis.

b) Low Serum albumin concentration is found in nephrotic syndrome due to proteinuria and cirrhosis of liver due to reduced synthesis of albumin. Low serum albumin concentration reduces the pressure gradient and hinders return of plasma water at the venous end of the capillary. Once fluid begins to accumulate in the interstitial fluid space, further accumulation of fluid occurs mainly through renal retention of sodium and water. The main stimulus for renal retention of sodium and water is decreased effective arterial volume which causes activation of two major hormones, namely aldosterone and vasopressin. By acting on the distal convoluted tubules and collecting tubules, these hormones enhance sodium and water reabsorption resulting in sustained edema.

\section{Generalized Edema (Anasarca)}

\subsection{Etiologies}

Anasarca is defined as generalized edema associated with hydrothorax (pleural effusion) and hydroperitoneum (ascites). Anasarca can occur due to a variety of conditions and can be conveniently divided on the basis of slight or heavy proteinuria.

\section{Common causes of Anasarca}

A1. Anasarca associated with significant proteinuria ( $>0.5 \mathrm{~g} / 24$ hours). Serum albumin is low to very low.

a) Primary and Secondary glomerular diseases.

b) Toxemia of Pregnancy.

c) Nephrosclerosis.

d) Severe or malignant hypertension.

e) Congenital Nephrotic syndrome.

A2. Anasarca associated with slight or no proteinuria ( $<0.5 \mathrm{~g} / 24$ hours). Serum albumin is low to very low.

a) Cirrhosis of liver. 
b) CHF.

c) Malnutrition.

d) Hypothyroidism.

A3. Edema (not necessarily anasarca) associated with vasodilator therapy. The following vasodilator drugs reduce blood pressure but also cause edema. These drugs are second generation dihydropyridine calcium channel blockers including nifedipine, amlodipine $\left(\right.$ Norvasc $^{\circledR}$ ) and felodipine (plendil ${ }^{\circledR}$ ). Other vasodilator drugs include minoxidil and nitrates.

A4. Uncommon causes of Anasarca.

a) Pelvic malignancy with spread into peritoneum.

b) Compression of superior or inferior vena cava by lymphoma, metastasis.

c) Lymphedema due to lymphatic obstruction by tumor, parasite (filarial). In this case, ascites is chylous.

\subsection{Therapy of Generalized Edema}

Generalized edema or anasarca is typically treated with one of the loop diuretics either given orally (PO) or by intravenous boluses.

\subsubsection{Oral Diuretic Therapy}

They are:

a) Furosemide $\left(\right.$ Lasix $\left.^{\circledR}\right)$.

b) Bumetanide (Bumex ${ }^{\circledR}$ ).

c) Torsemide (Demadex ${ }^{\circledR}$ ).

d) Ethacrynic Acid $\left(\right.$ Edecrin $\left.^{\circledR}\right)$.

All but the last loop diuretic are sulphonamide-derivative. Ethacrynic is a coal-tar derivative. Thus in those with history of allergy or dermatitis to sulfa drugs or with prior use of Lasix, edecrin will be the only safe loop diuretic to use. It is a common practice to prescribe furosemide boluses 20 to $40 \mathrm{mg}$ every 12 hours. The diuretic response depends on renal function. If renal function is normal response is good which means $5 \%$ of filtered water amounting to 8.5 liters urine per day. There are no reports available on the exact amount of diuresis with bolus therapy. However, diuretic response is directly proportional to the severity of renal dysfunction. Thus the response is small with estimated glomerular filtration rate (eGFR) of less than $30 \mathrm{ml} / \mathrm{min}(\mathrm{n} \geq 60 \mathrm{ml} / \mathrm{min}$ ) and minimal with eGFR of less than $10 \mathrm{ml} / \mathrm{min}$. The average dose of diuretic by boluses varies with clinical condition provided renal function is normal [1]. The reported average doses of diuretic are as follows.

Heart Failure: 40 to $80 \mathrm{mg}$ furosemide, 1 to $2 \mathrm{mg}$ bumetanide, or 20 to $40 \mathrm{mg}$ torsemide. Cirrhosis: $40 \mathrm{mg}$ furosemide, $1 \mathrm{mg}$ bumetanide or 10 to $20 \mathrm{mg}$ torsemide.

Nephrotic Syndrome: 80 to $120 \mathrm{mg}$ furosemide, 2 to $3 \mathrm{mg}$ bumetanide or 40 to $60 \mathrm{mg}$ torsemide.

Oral diuretic therapy is efficacious in producing adequate diuresis and reducing swelling in those with normal or near renal function characterized by eGFR $\geq 60 \mathrm{ml} / \mathrm{min}$. Overtime diuretic effect decreases with progressive loss of potassium in the urine, As intracellular potassium becomes severely depleted, sodium takes the place of potassium inside the cells and holds water thereby resurging edema, Thus effect of loop diuretic in reducing swelling can be maintained, if concomitantly spironolactone $25 \mathrm{mg}$ PO TID or amiloride $5 \mathrm{mg}$ PO daily is prescribed along with a loop diuretic. These potassium sparing drugs will reduce urinary potassium loss and conserve intracellular potassium content. As renal function decreases in course of time with continuous use of diuretic, edema becomes refractory, thus requiring much higher doses of a diuretic to produce the same or less than the previous response. Refractory state leads to bolus injections [2].

\subsubsection{Bolus Injections of Diuretic}

The following intravenous bolus doses of diuretic were recommended in refractory edema. The dose is usually given in 20 to 30 minutes.

Furosemide: $100 \mathrm{mg}$ to $200 \mathrm{mg}$.

Bumetanide: 8 to $10 \mathrm{mg}$.

Torsemide 50 to $100 \mathrm{mg}$.

The 2009 American College of Cardiology and American Heart Association guideline on heart failure recommended for patients with severe CHF the same intravenous dose of furosemide but a lower dose of bumetanide (4 to $8 \mathrm{mg}$ ) and a higher dose of torsemide (100 to $200 \mathrm{mg}$ ) [3]. 
Often the response of a loop diuretic is enhanced by adding hydrochlorothiazide 25 mg twice daily or metolazone $10 \mathrm{mg}$ daily. This is even more important when renal function is low (eGFR $<30 \mathrm{ml} / \mathrm{min}$ ) [4]

\subsubsection{Continuous Intravenous Infusion of Diuretic}

1) The rationale for a continuous intravenous infusion of a diuretic compared with bolus therapy is related to maintenance of an effective rate of drug excretion and therefore inhibition of sodium chloride reabsorption in the loop of Henle overtime. In contrast, bolus therapy is associated with initially higher and then lower rates of diuretic excretion, as a result, sodium excretion may be at near maximal levels for the first two hours but then decreases until the next dose is given.

A continuous intravenous infusion is safer in terms of ototoxicity than bolus injections of loop diuretics but evidence of diuretic efficacy is lacking. Urine output was significantly higher with a continuous infusion, although the difference was modest [5].

In a trial of eight patients with severe but stable chronic kidney disease (mean creatinine clearance of 17 $\mathrm{ml} / \mathrm{min}$ ) a continuous infusion of bumetanide (12 mg over 12 hours) was compared with two 6 mg boluses given at 0 and 6 hours. The boluses were given over 5 minutes period. The continuous infusion was associated with a significant 30 percent increase in sodium excretion during the study period (mean 236 vs 188 mmol). Total urinary bumetanide excretion during the study period was similar in the two groups [6].

2) Continuous Infusion of Bumetanide.

Having said the above the author cites his own experience with continuous bumetanide infusion. In the author's experience in a prospective fashion, continuous infusion of bumetanide is highly efficacious. However, the effectiveness varies with state of renal function and fluid overload. Theoretically, in a state of end stage renal disease with a serum creatinine $\geq 5 \mathrm{mg} / \mathrm{dl}$ or eGFR $\leq 10 \mathrm{ml} / \mathrm{min}$, no diuretic infusion may work. However, there are occasional patients with eGFR of $7 \mathrm{ml} / \mathrm{min}$ who superbly responded to bumetanide infusion with massive diuresis which was accompanied by significant recovery of renal function.

Bumetanide infusion in patients with markedly reduced kidney function.

Physiologically, the efficacy of continuous infusion of a diuretic should be proportional to the amount of diuretic excretion in the tubules. Thus when measured GFR or eGFR is low for instance, less than $30 \mathrm{ml} / \mathrm{min} \mathrm{pro}-$ portionately less diuretic excretion in the tubules, hence reduced response in terms of urine output is the expected outcome. However, Urine output may exceed the expected outcome.

Two patients are presented to demonstrate the efficacy of bumetanide infusion irrespective of state of renal function.

\section{Patient \#1}

A 70 years white male was admitted into a local hospital on May 19, 2014 with a history of abdominal cramp and watery diarrhea. He looked dry, was mildly febrile and showed low normal blood pressure. His renal function was reduced. BUN $37 \mathrm{mg} / \mathrm{dl}$ with eGFR $17 \mathrm{ml} / \mathrm{min}$. An ultrasound of kidneys revealed bilaterally small kidneys. No cause for small kidneys could be detected. His blood glucose levels were normal. He had low kidney function as far back as year 2003; serum creatinine was then $1.8 \mathrm{mg} / \mathrm{dL}$ ( $\mathrm{n} \leq 1.5 \mathrm{mg} / \mathrm{dL}$ ). He was initially treated with 5\% dextrose in water infusion for 24 hours after which he received sodium bicarbonate infusion, a premixed solution consisting of sodium bicarbonate $100 \mathrm{mEQ}$ in a liter of 0.45 percent saline solution.

Intravenous fluid therapy resulted in fluid overload with appearance of generalized edema and shortness of breath. Sodium bicarbonate infusion was discontinued on May 26, 2014. Bumetanide infusion (dose: 24 mg in $500 \mathrm{ml}$ normal saline) was administered at a rate of $21 \mathrm{ml}$ per hour starting May 27. The rate was reduced to 15 $\mathrm{ml} /$ hour after 48 hours. The infusion was discontinued after 72 hours. The results of bumetanide infusion are presented in Table 1.

As a result of bumetanide infusion for 3 days, he excreted 14,353 $\mathrm{ml}$ of urine. This is equivalent to $14.3 \mathrm{~kg}$ or 31.4 lbs fluid loss. Thus average loss of fluid was approximately 4.8 liters per day for 3 days. His edema and shortness of breath were markedly improved. His renal function was already reduced consistent with CKD stage 4, prior to bumetanide infusion. Renal function further decreased with fluid loss at a rapid rate. A replacement fluid consisting of isotonic saline ( $0.9 \%$ saline solution) was infused at a rate of $60 \mathrm{ml} /$ hour. The objective was to minimize decrease of Kidney function. A day later, his renal function improved, BUN, Serum creatinine and eGFR were $50 \mathrm{mg} / \mathrm{dL}, 3.22 \mathrm{mg} / \mathrm{dL}$ and $20 \mathrm{ml} / \mathrm{min}$, respectively.

\section{Patient \#2}

An 88 years old white American female was admitted into a local hospital in April of 2009 with a diagnosis 
Table 1. Intake, output, fluid balance and renal function changes.

\begin{tabular}{cccccccc}
\hline May 2014 & $\mathbf{2 5}$ & $\mathbf{2 6}$ & $\mathbf{2 7}$ & $\mathbf{2 8}$ & $\mathbf{2 9}$ & $\mathbf{3 0}$ \\
\hline & & & Bumetanide Infusion & & \\
\hline Total Intake (ml) & 3020 & 2530 & 1480 & 1619 & 3048 & 3060 \\
Total Output (ml) & 4000 & 2200 & 3200 & 8700 & 8600 & 2000 \\
Fluid Balance (ml) & -980 & +330 & -1720 & -7081 & -5552 & +1060 \\
BUN (mg/dL) & 32 & 27 & 22 & 26 & 38 & 49 \\
Serum Creatinine (mg/dL) & 2.50 & 2.36 & 2.11 & 2.41 & 3.11 & 3.50 \\
eGFR (ml/min) & 27 & 29 & 33 & 28 & 21 & 18 \\
\hline
\end{tabular}

of anasarca, CHF, lung cancer treated with chemotherapy and acute renal failure. She was so massively edematous that she could hardly move her legs. Treatment consisted of Lisinopril $10 \mathrm{mg}$ daily and furosemide 40 mg PO twice daily. Initial laboratory studies showed BUN $84 \mathrm{mg} / \mathrm{dl}$, serum creatinine $2.32 \mathrm{mg} / \mathrm{dL}$ with eGFR of $21 \mathrm{ml} / \mathrm{min}$. Lisinopril and furosemide were discontinued and she was treated with low dose bumetanide infusion $12 \mathrm{mg}$ in $500 \mathrm{ml}$ 5\% dextrose solution with delivery of $0.5 \mathrm{mg}$ bumetanide per hour. Her daily urine output (ml) is shown in Table 2.

She received replacement fluid from Day 2. At the end of bumetanide infusion, she was freely able to move her legs, breathing normally and eating well. Even with massive diuresis, her renal function improved. The results are shown in Table 3.

Even though serum creatinine decreased accompanied by increased eGFR, BUN decreased only slightly. What is the cause of this discrepancy in the reduction between BUN and serum creatinine.

Urea and creatinine have the same molecular weight and they have the same clearance in a normal kidney. It is important to know that creatinine is filtered by the glomeruli and secreted by the tubules, thus creatinine clearance represented by eGFR can be higher than Urea clearance. On the other hand, Urea is filtered by the glomeruli as well as reabsorbed by the tubules. The reabsorption of Urea by the tubules is mainly determined by urine flow. Thus the higher the urine flow lower is the reabsorption of urea by the tubules and lower will be blood urea nitrogen. More Importantly, Urea clearance is a function of renal blood flow. Thus, the higher is the renal blood flow, higher the urea clearance. Presumptively, renal blood flow is markedly decreased with eGFR of $21 \mathrm{ml} / \mathrm{min}$. Thus urea clearance will remain low accounting for much higher BUN compared to serum creatinine level. Whereas, as stated earlier, creatinine is secreted by the tubules increasing creatinine excretion and hence higher creatinine clearance is obtained. The result is lower serum creatinine with comparatively higher BUN. Thus the only way to increase urea clearance and decrease BUN is by artificial means which is dialysis.

In contrast, in those with normal kidney function, a diuretic infusion is unlikely to reduce kidney function except for a transient period. This is the illustrated in patient \#3.

\section{Patient Number \#3}

A 70 year white male was admitted into a local hospital in December 25, 2007 with history of increased shortness of breath and 50 lbs weight gain in a short time. He also gave a history of alcoholism and cirrhosis of liver. He was noted to be popped up in bed to help breathing, had anasarca and aortic stenosis which led to CHF. He was initially treated with furosemide $40 \mathrm{mg}$ intravenous boluses every 12 hours. He also received albumin infusion 25 g every 6 hours $\times 4$ doses. On January 4, 2008, furosemide boluses which produce slight relief were discontinued and started on continuous furosemide infusion (240 mg in $500 \mathrm{ml}$ of $5 \%$ dextrose in water), infused at a rate of $21 \mathrm{ml} /$ hour (delivering $43.7 \mathrm{mg}$ furosemide/hour).

The infusion rate was decreased to $15 \mathrm{ml} /$ hour (delivering $31.2 \mathrm{mg} /$ hour) after 72 hours and discontinued after 96 hours. The result of weight change, urine output and renal function changes are shown in Table 4.

Following furosemide infusion, he had complete remission of anasarca and was discharged home. At an office visit on January 23, 2008, his kidney function and electrolytes were normal. They were BUN $20 \mathrm{mg} / \mathrm{dL}$, serum creatinine $0.92 \mathrm{mg} / \mathrm{dL}$, and eGFR $>60 \mathrm{ml} / \mathrm{min}$, serum K $4.1 \mathrm{mmol} / \mathrm{L}$, respectively.

Bumetanide Infusion in Acute Congestive Heart Failure

A previous multicenter study on diuretic strategies in patients with acute decompensated heart failure found no significant differences in patients' global assessment of symptoms or change in renal function when diuretic therapy was administered by bolus as compared with continuous infusion [7]. 
Table 2. Urine output of day 1 - 5 bumetanide infusion.

\begin{tabular}{lc}
\hline Day 1 & 3800 \\
Day 2 & 7300 \\
Day 3 & 9000 \\
Day 4 & 6600 \\
Day 5 & 11,050 \\
Total Fluid Loss $=\mathbf{3 7 , 7 5 0} \mathbf{~ m l ~}=\mathbf{3 7 . 7} \mathbf{~ k g}$ \\
Average Fluid loss per day $=\mathbf{7 5 5 0} \mathbf{~ m l}$ \\
\hline
\end{tabular}

Table 3. Renal function changes before and after bumetanide infusion in patients \#2.

\begin{tabular}{ccc}
\hline & Before Infusion & After Infusion \\
\hline BUN (mg/dL) & 84 & 75 \\
Serum Creatinine (mg/dL) & 2.32 & 1.41 \\
eGFR (ml/min) & 21 & 38 \\
\hline
\end{tabular}

Table 4. Weight changes, Urine output and renal function changes.

\begin{tabular}{ccccc}
\hline 2008 January & $\begin{array}{c}\text { Weight } \\
\text { (pounds) }\end{array}$ & $\begin{array}{c}\text { Urine output } \\
\text { (ml/24hr) }\end{array}$ & $\begin{array}{c}\text { Fluid balance } \\
\text { (ml/24hr) }\end{array}$ & $\begin{array}{c}\text { Renal function Scr/eGFR } \\
\text { (mg/dL/ml/min) }\end{array}$ \\
\hline $\mathbf{4}$ & & Furosemide Infusion started & -1679 \\
$\mathbf{5}$ & 235 & 3200 & -3685 & Normal \\
$\mathbf{6}$ & 221 & 5500 & -5585 & Normal \\
$\mathbf{7}$ & 212 & 6625 & NA & NA
\end{tabular}

Total weight reduction $26 \mathrm{lbs}$ or $11.8 \mathrm{~kg}$ in 4 days

$\mathrm{NA}=$ not available; $\mathrm{Scr}$ = serum creatinine; eGFR = estimated glomerular filtration rate.

Adapted from the chapter on Generalized Edema (Anasarca): A systemic approach to Diagnostic and management. In Textbook of Nephrology Third Edition (Eds: Mandal AK, Prakash J) Jaypee Brothers Medical Publishers, New Delhi India, 2014 PP 112 - 124 with permission.

This study is another example of statistical jargon. The two modalities of diuretic therapy bolus vs continuous infusion is not statistically different thus undermining the explicable efficacy of diuretic infusion in particular, bumetanide infusion. Author's observation is contrary to that reported in the literature. A patient is presented here to illustrate just that. A 69 year African American female was admitted to a local hospital on May 30, 2014 with severe shortness of breath. Physical examination was difficult as she was unable to lie down. She was always sitting up in bed for breath and to sleep. She shows no edema, however. Her laboratory testing were Na $138 \mathrm{mmol} / \mathrm{L}$, K $3.1 \mathrm{mmol} / \mathrm{L}$, Chloride $101 \mathrm{mmol} / \mathrm{L}, \mathrm{CO}_{2} 34 \mathrm{mmol} / \mathrm{L}$, glucose $101 \mathrm{mg} / \mathrm{dL}$, BUN $21 \mathrm{mg} / \mathrm{dl}$, serum creatinine $1.4 \mathrm{mg} / \mathrm{dL}$, eGFR $40 \mathrm{ml} / \mathrm{min}$, albumin $3.5 \mathrm{~g} / \mathrm{dL}$, calcium $9.1 \mathrm{mg} / \mathrm{dL}$, uric acid $8.6 \mathrm{mg} / \mathrm{dL}$ She was treated with furosemide boluses every 12 hours as well as P.O. metolazone which gave her no or slight symptomatic relief. Her brain natriuretic peptide (BNP) before admission was $2336 \mathrm{pg} / \mathrm{mL}$.

She was started on bumetanide (bumex ${ }^{\circledR}$ ) infusion ( $24 \mathrm{mg}$ in $500 \mathrm{ml}$ normal saline) at a rate of $21 \mathrm{ml}$ per hour on May 31, 2014 and continued for 96 hours. Bumetanide infusion was discontinued on June 4, 2014. Her intake, output, fluid and BNP are presented in Table 5.

By treatment with bumetanide infusion, she progressively felt complete relief from shortness of breath, could lie flat and sleep well. These subjective improvements are consequent to total fluid loss of 17.5 liters with an average of $4369 \mathrm{ml}$ fluid per day. This subjective improvement is accompanied by objective improvement characterized by progressive decline in BNP from $1448 \mathrm{pg} / \mathrm{ml}$ before infusion to $257 \mathrm{pg} / \mathrm{ml}$ (85 percent decrease) after 96 hours of bumetanide infusion. Therefore this piece of data is a solitary but discrete evidence of effectiveness of continuous bumetanide infusion in the treatment of acute or chronic congestive heart failure.

Commonly, renal function decreases and electrolytes imbalances occur but these are reversible with replace- 
ment of fluid and electrolytes Thus vigilant monitoring of the patient(s) during diuretic infusion by a nephrologist or a physician knowledgeable in fluid and electrolyte therapy is essential to minimize the adverse effects.

The adverse effects on renal function and electrolytes and their corrections are shown in Table 6.

She was treated with replacement fluid (isotonic saline solution with Kcl $20 \mathrm{mEQ}$ added in the bag), Kcl 20 mEQ PO, TID and amiloride $10 \mathrm{mg}$ PO daily.

Now it is evident that renal function, electrolytes and acid base disorders are reversible with infusion of normal saline with $\mathrm{K}$ supplement and sometime magnesium and phosphorus replacement. Added to the panorama of problem is the metabolic alkalosis characterized by progressive increase of $\mathrm{HCO}_{3}$ level accompanied by increase of $\mathrm{PCO}_{2}$ as shown in this patient (Table 6). Normal saline infusion enhances bicarbonate excretion but may not be adequate thus requiring additionally acetazolamide to promote bicarbonate excretion and reducing $\mathrm{pH}$ and $\mathrm{PCO}_{2}$ to normal levels. She received acetazolamide $500 \mathrm{mg}$ IV Q 8 hours $\times 72$ hours. Her renal function returned to baseline level and serum $\mathrm{K}$, and $\mathrm{CO}_{2}$ became near-normal.

\subsubsection{Concomitant Albumin Infusion}

In those with low serum albumin ( $<3 \mathrm{~g} / \mathrm{dL}$ or $30 \mathrm{~g} / \mathrm{L}$ ) which is common in nephrotic syndrome, cirrhosis of liver or CHF, conventional practice is to administer 12.5 to $25 \mathrm{~g}$ salt poor albumin every 6 to 8 hours during the period of diuretic infusion. The idea is to increase binding of diuretic to albumin and thereby increase the delivery of diuretic at the tubular site of action. In the initial report, this approach led to a substantial increase in sodium excretion in some patients [8].

Table 5. Intake, output, fluid balance and BNP.

\begin{tabular}{|c|c|c|c|c|}
\hline May-June 2014 & Intake (ml/24h) & Output (ml/24h) & Fluid balance + or $-\mathrm{ml} / 24 \mathrm{~h}$ & $\operatorname{BNP}(n=15=100 \mathrm{pg} / \mathrm{ml})$ \\
\hline June 1 & 2170 & 2600 & -430 & 1448 \\
\hline June 2 & 1476 & 8750 & -7274 & 762 \\
\hline June 3 & 2202 & 10,050 & -7848 & 552 \\
\hline June 4 & 2975 & 4900 & -1925 & 324 \\
\hline \multicolumn{5}{|c|}{ Infusion Discontinued } \\
\hline June 5 & 3105 & 3700 & -595 & 257 \\
\hline June 6 & 2060 & 1000 & +1060 & 290 \\
\hline June 7 & NA & NA & NA & 483 \\
\hline
\end{tabular}

Table 6. The adverse effects on renal function and electrolytes and their corrections.

\begin{tabular}{|c|c|c|c|c|c|}
\hline June 2014 & BUN (mg/dL) & Scr (mg/dL) & eGFR (ml/min) & $\mathrm{K}(\mathrm{mmol} / \mathrm{L})$ & $\mathrm{CO}_{2}(\mathrm{mmol} / \mathrm{L})$ \\
\hline June 1 & 31 & 1.53 & 36 & 3.2 & 35 \\
\hline June 2 & & & \multicolumn{2}{|c|}{$\mathrm{ABG}$} & $\begin{array}{rll}\mathrm{HCO}_{3} & 45.1 \\
\mathrm{PCO}_{2} & 62 & \mathrm{mmHg}\end{array}$ \\
\hline June 3 & 49 & 1.90 & 28 & 2.7 & 42 \\
\hline June 4 & & & \multicolumn{2}{|c|}{ ABG } & 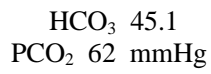 \\
\hline June 4 & 64 & 2.20 & 24 & 2.9 & 42 \\
\hline June 5 & 68 & 2.33 & 22 & 2.9 & 39 \\
\hline June 6 & & & \multicolumn{2}{|c|}{$\mathrm{ABG}$} & $\begin{array}{rll}\mathrm{HCO}_{3} & 45.1 \\
\mathrm{PCO}_{2} & 62 & \mathrm{mmHg}\end{array}$ \\
\hline June 6 & 62 & 1.85 & 29 & 3.2 & 33 \\
\hline June 7 & 56 & 1.61 & 34 & 3.8 & 30 \\
\hline
\end{tabular}


The benefit of concomitant albumin infusion during the period of diuretic infusion cannot be ascertained from the scarce literature information and limited author's personal experience. In addition, there is a distinct risk of albumin infusion leading to severe CHF in those with impaired heart function. Thus, considering this risk, caution must be exercised for albumin infusion and in particular in those with CHF, albumin infusion may be avoided.

\subsubsection{Replacement of Fluid and Electrolytes}

Intravascular fluid space and effective circulating volume will rapidly decrease leading to decrease in kidney function which will rapidly decrease diuretic response.

To avoid these consequences, it is important to replace at least $20 \%$ to $25 \%$ of daily urine output by replacement fluid. Since sodium is lost hugely with diuretic infusion, isotonic saline $(0.9 \%)$ solution is the ideal solution and to be infused at a rate of 50 to $75 \mathrm{ml} /$ hour delivering 1200 to $1800 \mathrm{ml}$ per 24 hour depending on the urine flow rate and the renal function changes. Potassium is the most common electrolyte lost and can be replaced in the fluid as 20 to $40 \mathrm{mEQ}$ in the liter fluid bag. Potassium loss can also be replaced by $\mathrm{PO} \mathrm{KCl} 20$ mEQ PO BID or TID.

\subsubsection{Adjuvant Therapy}

The following electrolytes and acid loss can be massive and need replacement.

These are:

1) Potassium.

2) Magnesium.

3) $\mathrm{H}+$ Ions.

Hydrogen Ions are excreted along with potassium leading to hypokalemia and metabolic alkalosis. As K decreases $\mathrm{CO}_{2}$ increases which are found in basic metabolic panel. Exact severity of metabolic alkalosis can be determined by ordering arterial blood gas analysis as already shown in Table 6 . Both can be treated by adding $\mathrm{Kcl}$ in the saline infusion bag in dose of $40 \mathrm{mmol} / \mathrm{L}$ bag. Chloride will be absorbed and bicarbonate will be excreted. If pH goes above 7.50, acetazolamide $500 \mathrm{mg}$ IV every 8 - 12 hour can be given to enhance bicarbonate excretion and reduce alkalemia. To control hypokalemia fast, $\mathrm{K}$ sparing agents such as spironolactone 100 to $200 \mathrm{mg}$ PO daily in divided doses or amiloride 5 to $10 \mathrm{mg}$ daily can be used. These agents will enhance diuresis to an extent. However, risk of hypokalemia will be reduced.

Magnesium is typically administered as $2 \mathrm{~g}$ in $250 \mathrm{ml}$ vehicle for 2 hours. However, intravenous magnesium is rapidly excreted in the urine and serum level decreases again. On the other hand, magnesium sulfate $50 \%$ solution $2 \mathrm{ml}(1 \mathrm{~g})$ IM can be given every 6 hours for 4 doses depending on the serum magnesium level will correct hypomagnesemia fast and in a sustained fashion.

\section{Adverse Effect of Diuretic Therapy}

The following adverse effect may be observed associated with diuretic infusion.

1) Cramps in the extremities due to rapid fluid loss as well loss of electrolytes. If cramping is severe, diuretic infusion rate should be reduced and isotonic saline solution with $\mathrm{KCl}$ shall be administered in the rate stated before.

2) Ototoxicity has been reported following bolus intravenous therapy of loop diuretic [9]. Ototoxicity has not been experienced by the author with continuous infusion of bumetanide or furosemide.

\section{Maintenance Therapy Following Diuretic Infusion}

Typically author prescribes bumetanide P.O. $2 \mathrm{mg}$ BID as infusion rate is decreased or when the infusion is stopped. Maintenance PO therapy should be started at least 48 hours before discontinuation of infusion. There is no systemic study done to validate the efficacy of maintenance therapy following continuous infusion.

\section{Pearl of Wisdom}

1) Continuous infusion of furosemide or bumetanide is a very effective way to treat generalized edema. Either infusion is very effective in producing subjective improvement of shortness of breath in CHF. 
2) The efficacy is essentially similar with normal or reduced renal function.

3) Although the response of bumetanide infusion seems to be greater but its superiority over furosemide infusion is difficult to ascertain without crossover study.

4) No serious adverse effect has been observed except hypokalemia, hypomagnesaemia and metabolic alkalosis. All these adverse effects are reversible and are easily treatable with adjuvant therapy as already stated.

5) Thus, continuous diuretic (furosemide or bumetanide) infusion shall be considered as an effective therapy albeit conservative substitute of dialysis therapy for patients with massive edema and markedly reduced kidney function such as stages 4-6 chronic kidney disease or acute or chronic CHF without or with reduced kidney function.

\section{References}

[1] Brater, D.C. (1998) Diuretic Therapy. The New England Journal of Medicine, 339, 387-395. http://dx.doi.org/10.1056/NEJM199808063390607

[2] Voelker, J.R., Cartwright-Brown, D., Anderson, S., Leinfelder, J., Sica, D.A., Kokko, J.P., Brater, D.C. (1987) Comparison of Loop Diuretics in Patients with Chronic Renal Insufficiency. Kidney International, 32, 572-578. http://dx.doi.org/10.1038/ki.1987.246

[3] Hunt, S.A., Abraham, W.T., Chin, M.H., Feldman, A.M., Francis, G.S., Ganiats, T.G., Jessup, M., Konstam, M.A., Mancini, D.M., Michl, K., Oates, J.A., Rahko, P.S., Silver, M.A., Stevenson, L.W. and Yancy, C.W. (2009) Focused Update Incorporated into the ACC/AHA 2005 Guidelines for the Diagnosis and Management of Heart Failure in Adults: A Report of the American College of Cardiology Foundation/American Heart Association Task Force on Practice Guidelines: Developed in Collaboration with the International Society for Heart and Lung Transplantation. Circulation, 119, e391-e479. http://dx.doi.org/10.1161/CIRCULATIONAHA.109.192065

[4] Dargie, H.J., Marjorie, E.M., Allison, A., Kennedy, Mary, C.J. and Gray, B. (1972) High Dosage Metolazone in Chronic Renal Failure. British Medical Journal, 2, 196-198. http://dx.doi.org/10.1136/bmj.4.5834.196

[5] Salvador, D., Rey, N.R., Ramos, C.A.C. and Punzalan, F.E. (2005) Continuous Infusion versus Bolus Injection of Loop Diuretics in Congestive Heart Failure. Cochrane Database of Systematic Reviews, 1, Article ID: CD003178.

[6] Rudy, D.W., Voelker, J.R., Greene, P.K., Esparza, F.A., Brater, D.C. (1991) Loop Diuretics for Chronic Renal Insufficiency: A Continuous Infusion Is More Efficacious than Bolus Therapy. Annals of Internal Medicine, 115, 360-366. http://dx.doi.org/10.7326/0003-4819-115-5-360

[7] Felker, G.M., Lee, K.L., Bull, D.A., Redfield, M.M., Stevenson, L.W., Goldsmith, S.R., LeWinter, M.M., Deswal, A., Rouleau, J.L., Ofili, E.O., Anstrom, K.J., Hernandez, A.F., McNulty, S.E., Velazquez, E.J., Kfoury, A.G., Chen, H.H., Givertz, M.M., Semigran, M.J., Bart, B.A., Mascette, A.M., Braunwald, E. and O’Connor, C.M., NHLBI Heart Failure Clinical Research Network (2011) Diuretic Strategies in Patients with Acute Decompensated Heart Failure. The New England Journal of Medicine, 364, 797-805.

[8] Inoue, M., Okajima, K., Itoh, K., Ando, Y., Watanabe, N., Yasaka, T., Nagase, S. and Morino, Y. (1987) Mechanism of Furosemide Resistance in Analbuminemic Rats and Hypoalbuminemic Patients. Kidney International, 32, 198-203. http://dx.doi.org/10.1038/ki.1987.192

[9] Gallagher, K.L. and Jones, J.K. (1979) Furosemide Ototoxicity. Annals of Internal Medicine, 91, 744-745. http://dx.doi.org/10.7326/0003-4819-91-5-744 
Scientific Research Publishing (SCIRP) is one of the largest Open Access journal publishers. It is currently publishing more than 200 open access, online, peer-reviewed journals covering a wide range of academic disciplines. SCIRP serves the worldwide academic communities and contributes to the progress and application of science with its publication.

Other selected journals from SCIRP are listed as below. Submit your manuscript to us via either submit@scirp.org or Online Submission Portal.
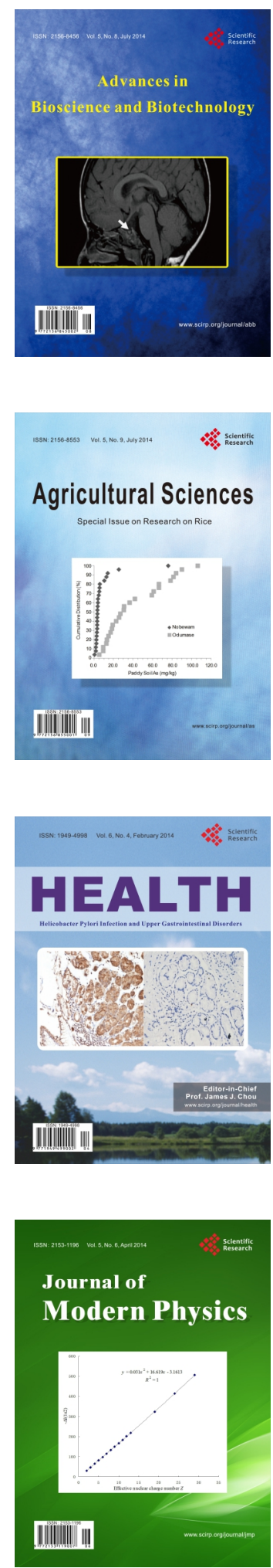
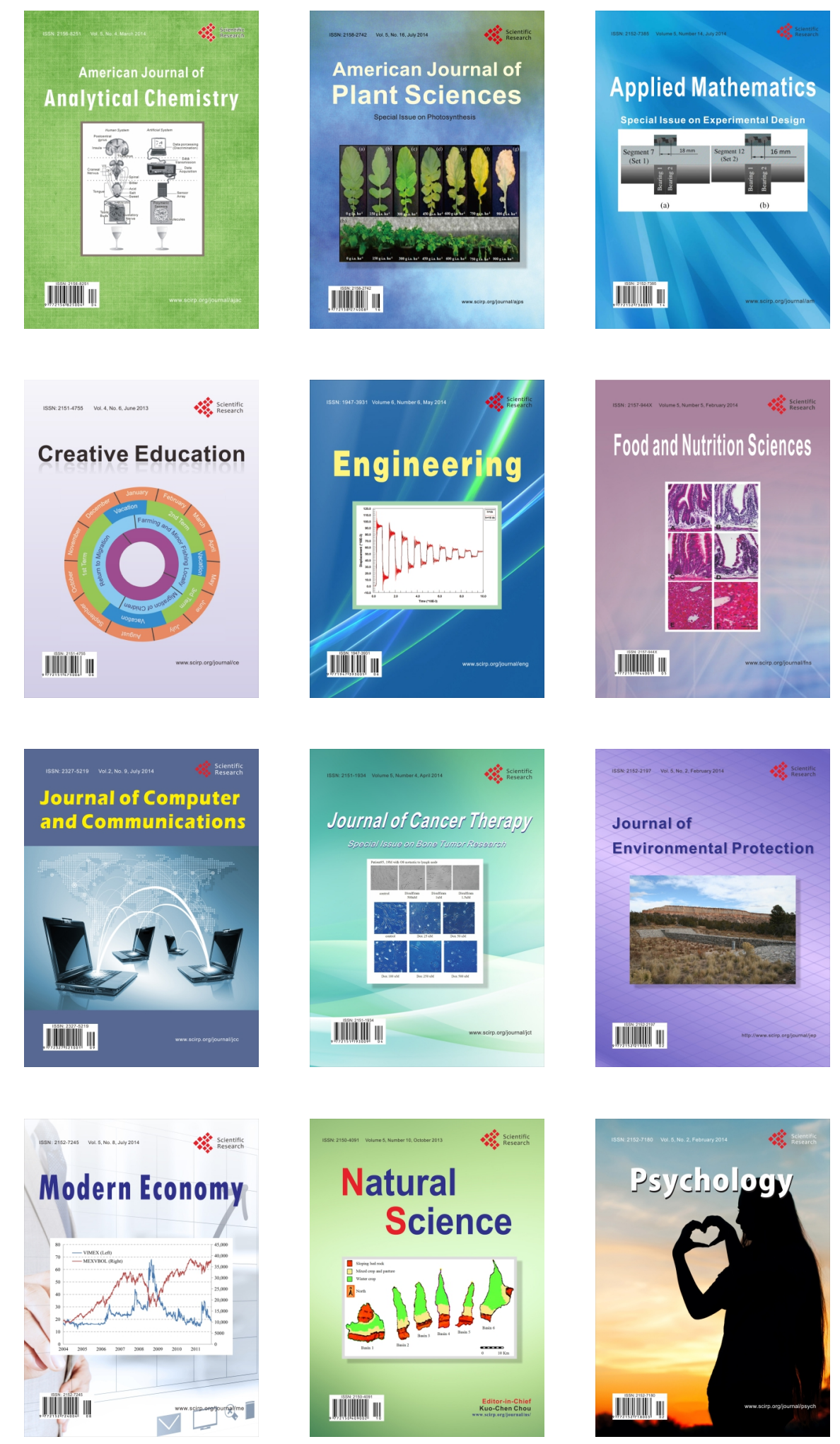